\title{
A new anthropometric index for body fat estimation in patients with severe obesity

\author{
Giliane Belarmino ${ }^{1 *}$, Raquel S. Torrinhas ${ }^{1}$, Priscila Sala ${ }^{1}$, Lilian M. Horie ${ }^{1}$, Lucas Damiani ${ }^{2}$, Natalia C. Lopes ${ }^{1}$, \\ Steven B. Heymsfield ${ }^{3}$ and Dan L. Waitzberg ${ }^{1}$
}

\begin{abstract}
Background: Body mass index (BMI) has been used to assess body adiposity, but it cannot adequately reflect body fat (BF) amount. The body adiposity index (BAI) has been shown a better performance than BMI for this purpose, but it can be inaccurate to estimate $\mathrm{BF}$ under extreme amounts of fat. Here, we propose a new anthropometric index, the Belarmino-Waitzberg (BeW) index, for specific estimation of BF in severely obese patients.

Methods: In 144 adult patients with severe obesity, BF was estimated by air displacement plethysmography (ADP), as the reference method, along with the follow anthropometric measurements: height, abdominal circumference (AC), hip circumference $(\mathrm{HC})$, weight, BMI (weight/ height $\left.{ }^{2}\right)$ and BAl $\left(\left[\mathrm{HC}(\mathrm{cm}) /\right.\right.$ height $\left.\left.\left.(\mathrm{m})^{1.5}\right)-18\right] \times 100\right)$. Patients were proportionately distributed into two distinct databases, the building model database (BMD) and the validation model database (VMD), which were applied to develop and validate the BeW index, respectively. The BeW index was tested for gender and ethnicity adjustment as independent variables. The agreement of BF\% values obtained by the new index and by BAI with ADP was also assessed.
\end{abstract}

Results: The BF\% was $52.05 \pm 5.42$ for ADP and $59.11 \pm 5.95$ for the BeW index (all results are expressed as the mean \pm standard deviation). A positive Pearson correlation ( $r=0.74)$, a good accuracy $(\mathrm{Cb}=0.94)$, and a positive Lin's concordance correlation (CCC $=0.70$ ) were observed between the two groups. The $95 \%$ limits of individual agreement between the BeW index and ADP were 6.8 to $7.9 \%$, compared to -7.5 to $14.8 \%$ between the BAl and ADP. The new index, called the Belarmino-Waitzberg (BeW) index, showed an improvement of $2.1 \%$ for the $\mathrm{R}^{2}$ value and a significant gender effect, therefore resulting in two different indexes for females and males, as follows: Female $\mathrm{BeW}=-48.8+0.087 \times \mathrm{AC}(\mathrm{cm})+1.147 \times \mathrm{HC}(\mathrm{cm})-0.003 \times \mathrm{HC}(\mathrm{cm}) 2$ and Male $\mathrm{BeW}=-48.8+0.087 \times \mathrm{AC}(\mathrm{cm})+1.147 \times$ $\mathrm{HC}(\mathrm{cm})-0.003 \times \mathrm{HC}(\mathrm{cm}) 2-7.195$.

Conclusions: The new BeW index showed a good performance for BF estimation in patients with severe obesity and can be superior to the BAl for this purpose.

Keywords: Severe obesity, Body fat, Body adiposity index, Air displacement plethysmography

\section{Background}

The obesity epidemic is now a major public health concern due its impact on health and the economy. Characterized by abnormal body fat (BF) accumulation, obesity is linked with several debilitating diseases and an increased mortality [1]. An accurate diagnosis of obesity can guide clinical management and treatments.

\footnotetext{
* Correspondence: giliane85@hotmail.com

'Department of Gastroenterology, Surgical Division, LIM 35, Faculdade de Medicina da Universidade de São Paulo, Av. Dr. Arnaldo, 455, $2^{\circ}$ andar, sala 2208, São Paulo, Cerqueira César CEP: 01246-903, Brazil

Full list of author information is available at the end of the article
}

The body mass index (BMI) has been widely applied to identify and classify obesity. However, the BMI cannot fully reflect the amount and distribution of $\mathrm{BF}$ or clearly distinguish the fat-free mass from fat mass compartments. Particularly, the BMI performance in severely obese patients is impaired by the large amount of subcutaneous adipose tissue and edema [2, 3].

$\mathrm{BF}$ assessment is more precise in obese subjects when more specific methods for body composition evaluation are used. Air displacement plethysmography (ADP) is a scientific validated reference method to evaluate body

(C) The Author(s). 2018 Open Access This article is distributed under the terms of the Creative Commons Attribution 4.0 International License (http://creativecommons.org/licenses/by/4.0/), which permits unrestricted use, distribution, and 
composition in obese subjects [4]. The method uses air displacement after patient entry in the ADP device to assess BF, by applying the Boyle's Law [5]. ADP has several advantages over other reference methods for BF assessment, including a quick noninvasive measurement process [5]. The main limitation in the routine application of ADP or other similar available tools for BF assessment is its high cost and practical complexity. Therefore, other alternative methods for BF assessment have been proposed.

In particular, the body adiposity index (BAI) has been found to be more sensitive to identify and classify obesity than the BMI, compared to dual-energy X-ray absorptiometry (DXA), as the reference method [6]. The BAI provides a practical advantage because it uses a simple equation for calculation that includes only hip circumference $(\mathrm{HC})$ and body height. Furthermore, the BAI was developed from a database composed of adult Mexican-American men and further successfully validated in adult African-American men and women, suggesting that it could be applied universally without adjustments for gender or race.

Nevertheless, studies applying the BAI have shown its limited performance for BF estimation in populations with extreme amounts of fat (very low or very high) [7-9]. In particular, we have recently shown that the BAI poorly estimates BF in severely obese patients. Therefore, the aim of the current study was to design a new index to estimate BF in patients with severe obesity using simple and accessible anthropometric measurements.

\section{Methods}

\section{Study protocol and design}

Our study protocol was designed to develop a new anthropometric index for BF estimation in severely obese patients. For this purpose, our obese patient sample was composed of two proportional and distinct databases: the building model database (BMD), composed of the same 72 patients for whom we previously found a low performance of the BAI in estimating BF [10]; and the validation model database (VMD), composed of new 72 paired obese patients. The BMD was applied to develop the new index from anthropometric data potentially predictive of $\mathrm{BF}$, using the BF\% obtained by ADP as reference standard. The VMD was applied to validate the new index by assessing its performance in estimating BF in a similar population. For this purpose, the correlation and agreement between the $\mathrm{BF}$ values estimated by the new index with the BF values estimated by ADP were assessed. Furthermore, the agreement between the $\mathrm{BF}$ values estimated by $\mathrm{BAI}$ with the $\mathrm{BF}$ values estimated by $\mathrm{ADP}$ also was assessed to identify the performance of BAI comparative to the new index. For all the analyses, each patient was evaluated on the same day, in the morning, and after a 4-h overnight fast. Patients were instructed not to smoke or to drink alcohol during the $24 \mathrm{~h}$ prior to measurements, which were performed by the same trained technician for all enrolled patients.

\section{Patients}

Sample size calculations were based on the development of a model with nine possible predictors, with an effect size of at least 0.15 and considering an alpha value of $5 \%$ and a power of $95 \%$ [11]. A total of 144 severely obese Brazilian patients (108 female, 36 male) aged 18-55 years old, who were candidates for bariatric surgery and each of whom had a BMI $\geq 30 \mathrm{~kg} / \mathrm{m}^{2}$ (range: $30-62 \mathrm{~kg} / \mathrm{m}^{2}$ ), were recruited from the Digestive Tract Surgery Service at the Hospital das Clinicas - University of São Paulo School of Medicine, São Paulo, Brazil. The exclusion criteria were neurologic or psychiatric conditions; substance abuse; lactating or pregnant women; HIV-positive or cancer patients; clinically detectable edema; physical amputations; and chronic or acute diseases of the liver, lung, kidney, or heart. All study procedures were performed according to the ethical standards of the World Medical Association's Declaration of Helsinki. These and both datasets (building and validation) were approved by the institutional ethics review board - CAPPesq (1069/05 and 1011/09). Written informed consent was obtained from each patient prior to participation.

\section{Anthropometric data}

Each anthropometric data corresponds to an average of 3 sequentially repeated measures, which were performed as previously described elsewhere [10]. Briefly, body weight $(\mathrm{kg}$, minimal variation of $10 \mathrm{~g}$ ) was measured by using the weekly-calibrated body weight scale of the ADP system (Bod Pod body composition system, Life Measurement Instruments, Concord, CA, USA), with the patient standing in the center of the scale platform, barefoot, and wearing only underwear. Body height $(\mathrm{cm})$ was obtained with a stadiometer (Sanny, São Paulo, Brazil), with the patient standing, barefoot with the heels together, back upright, and arms stretched next to the body. The abdominal circumference (AC) was measured using an inelastic metrical tape at the trunk midway between the lower costal margin (bottom of the lowest rib) and the iliac crest (top of the pelvic bone), with the patient standing with his/her feet $25-30 \mathrm{~cm}$ apart. The measurement was taken by fitting the tape snugly, without compressing the underlying soft tissue. Circumference was measured to the nearest $0.5 \mathrm{~cm}$, at the end of a normal expiration [12]. The $\mathrm{HC}(\mathrm{cm})$ was measured by positioning a measuring tape in the horizontal plane at the greatest circumference of the buttocks $[6,13]$. In addition, the BMI was calculated as body weight (kg) / 
[height $(\mathrm{m})]^{2}$ and classified according to the World Health Organization scoring system $[14,15]$.

\section{BF estimation by the BAI}

The following equation was used to estimate $\mathrm{BF}$ by the BAI: $\mathrm{BF} \% \mathrm{BAI}=\left[\left(\mathrm{HC}(\mathrm{cm}) /\right.\right.$ height $\left.\left.(\mathrm{m})^{1.5}\right)-18\right] \times 100^{6}$.

\section{BF estimation by ADP}

Using the Bod Pod, ADP was performed to estimate the total BF. In the ADP method, the inverse relationship between pressure and volume proposed by Boyle $(\mathrm{P} 1 \times \mathrm{V} 1=\mathrm{P} 2 \times \mathrm{V} 2)$ was used to determine the body volume. Skin surface area artefact $(S A A)$ also was calculated by the BOD POD software to allow changes in air temperature close to the subject's skin. Body volume (BV) and body density (BD) were then calculated as $\mathrm{V}(\mathrm{L})$ $=$ BVraw $-S A A(\mathrm{~L})+40 \% T G V(\mathrm{~L})$ and $\mathrm{BF} \%$ was then calculated using Siri's equation: $B F \%=(4.95 / D-4.5) \times 100$, where $\mathrm{D}=$ density. All measurements and calculations were automatically performed by the system software, and they are based on air volume and pressure variations inside the Bod Pod chamber when occupied and not occupied by the patient $[12,16]$. During ADP evaluations, the patients wore only underwear and a cap to keep their hair fastened, and they remained in a sitting position inside the chamber [12]. Metallic objects, such as earrings, rings, chains, and body piercings, were not allowed.

\section{New index design}

Values of BF\% obtained by ADP from the BMD were correlated with anthropometric data. Variables with a significant concordance with the $\mathrm{BF} \%$ values provided by ADP were included in the initial index model and tested for the influence of gender and race by polynomial regression. The Akaike criterion was applied to select the variables to be used in the final index model, and a backward linear regression was applied to develop the specific BF prediction equation.

\section{New index test for validation and performance}

The agreement between the BF values from the ADP system with the two new BF equations and BAI were assessed according to the Pearson correlation, ( $r$ ), accuracy $(\mathrm{Cb})$, Lin's concordance correlation coefficient (CCC) and the Bland-Altman plot.

\section{Statistical analysis}

In addition to the statistical analysis described above for the development of validation of the new equation, descriptive data were compared by the Student's unpaired $\mathrm{t}$ - test or the Mann-Whitney U-test, when appropriate. All statistical analyses were performed using the $R$ software package (version 3.1.0, R Development Core Team, 2014). The results are expressed as the mean \pm standard deviation. Statistical significance was set at $p<0.05$ for all tests.

\section{Results}

\section{Descriptive data}

Table 1 provides the baseline demographic, body composition, and anthropometric data of the studied obese patients, divided in into the $\operatorname{MBD}(n=72)$ and MVD $(n=72)$ as well as the total $(n=144)$. From the entire sample, most of the patients were women (70\%), the BMI ranged from 34.40 to $62.98 \mathrm{~kg} / \mathrm{m}^{2}$, with $92 \%$ of patients having BMI $>40 \mathrm{~kg} / \mathrm{m}^{2}$; age ranged from 18 to 62 years old; and the mean $\mathrm{BF} \%$ estimates measured by ADP was $52.05 \pm 5.42 \%$.

\section{New anthropometric index design}

Data of BF\% estimated by ADP significantly correlated with the following individual anthropometric data: body weight, AC, waist-hip ratio (negative correlation), and $\mathrm{HC}(p \leq 0.05$; Table 2$)$. $\mathrm{HC}$ was the variable with the higher significant correlation with BF\% estimated by ADP $(p<0001)$ and then was tested for gender and race adjustments. HC shows to be significantly influenced by gender, by

Table 1 Demographic, body composition, and anthropometric data of severely obese patient samples

\begin{tabular}{|c|c|c|c|c|}
\hline Variable & MBD & MVD & Total $(n=144)$ & $\begin{array}{l}P \\
\text { value }\end{array}$ \\
\hline Gender (female) & $\begin{array}{l}53 / 72 \\
(73.6 \%)\end{array}$ & $\begin{array}{l}55 / 72 \\
(76.4 \%)\end{array}$ & $\begin{array}{l}108 / 144 \\
(75.0 \%)\end{array}$ & 0.847 \\
\hline Gender (male) & $\begin{array}{l}19 / 72 \\
(26.4 \%)\end{array}$ & $\begin{array}{l}17 / 72 \\
(23.6 \%)\end{array}$ & $36 / 144(25.0 \%)$ & 0.281 \\
\hline Race (white) & $\begin{array}{l}46 / 72 \\
(63.9 \%)\end{array}$ & $\begin{array}{l}53 / 72 \\
(73.6 \%)\end{array}$ & $99 / 144(68.8 \%)$ & \\
\hline $\begin{array}{l}\text { Race (black/ } \\
\text { brown) }\end{array}$ & $\begin{array}{l}26 / 72 \\
(36.1 \%)\end{array}$ & $\begin{array}{l}26 / 72 \\
(36.1 \%)\end{array}$ & 45/144 (31.2\%) & 0.877 \\
\hline Age (years) & $42.58 \pm 12.32$ & $42.88 \pm 10.07$ & $42.73 \pm 11.21$ & 0.318 \\
\hline Body weight (kg) & $127.68 \pm 27.5$ & $\begin{array}{l}123.33 \pm \\
24.53\end{array}$ & $125.51 \pm 26.06$ & 0.386 \\
\hline Height (m) & $1.63 \pm 0.1$ & $1.62 \pm 0.1$ & $1.63 \pm 0.1$ & 0.532 \\
\hline BMI $\left(\mathrm{kg} / \mathrm{m}^{2}\right)$ & $47.45 \pm 6.75$ & $46.77 \pm 6.23$ & $47.11 \pm 6.48$ & 0.719 \\
\hline$A C(\mathrm{~cm})$ & $\begin{array}{l}137.46 \pm \\
17.38\end{array}$ & $\begin{array}{l}136.49 \pm \\
14.83\end{array}$ & $136.97 \pm 16.11$ & 0.728 \\
\hline $\mathrm{HC}(\mathrm{cm})$ & $\begin{array}{l}135.21 \pm \\
13.83\end{array}$ & $\begin{array}{l}136.02 \pm \\
13.97\end{array}$ & $135.61 \pm 13.86$ & 0.565 \\
\hline Waist-hip ratio & $1.02 \pm 0.11$ & $1.01 \pm 0.11$ & $1.01 \pm 0.11$ & 0.847 \\
\hline ADP BF\% & $52.14 \pm 5.4$ & $51.96 \pm 5.47$ & $52.05 \pm 5.42$ & 0.300 \\
\hline
\end{tabular}

Data were obtained from 144 patients and are expressed as the mean \pm standard deviation. $M B D$ model building database, $M V D$ model validation database, $B M I$ body mass index, $A C$ abdominal circumference, $H C$ hip circumference, $A D P B F \%$ values of body fat percentage estimated by air displacement plethysmography 
Table 2 Pearson's correlation coefficient of body fat values (\%) estimated by air displacement plethysmography and anthropometric variables from building database

\begin{tabular}{llll}
\hline Variable & $r$ & $95 \% \mathrm{Cl}$ & $p$ Value* \\
\hline Body weight $(\mathrm{kg})$ & 0.26 & $0.03-0.46$ & 0.028 \\
Height $(\mathrm{m})$ & -0.16 & $-0.37-0.08$ & 0.19 \\
$\mathrm{AC}(\mathrm{cm})$ & 0.27 & $0.04-0.47$ & 0.022 \\
HC $(\mathrm{cm})$ & 0.59 & $0.41-0.72$ & $<0.001$ \\
Waist-hip ratio & -0.24 & $-0.45--0.01$ & 0.042 \\
\hline
\end{tabular}

Data were obtained from 72 obese patients. $A C$ abdominal circumference, $H C$ hip circumference

displaying a nonlinear dispersion with BF\% estimated by ADP (Fig. 1). Therefore, the initial model aimed to join two factors: the highly significant nonlinearity of $\mathrm{HC}$ (compared to $\mathrm{BF} \%$ ) and the inclusion of body weight and/or AC as potential additional predictive variables of BF adjusted by gender and race. The quadratic effect of the interaction between $\mathrm{HC}$, body weight, and $\mathrm{AC}$ data with gender and race showed that only the $\mathrm{HC}$ (quadratic) presented significant results (Table 3). Therefore, by using the Akaike criteria, the new anthropometric index was simplified to the factors shown in Table 4. The new index, called the Belarmino-Waitzberg (BeW) index, showed an improvement of $2.1 \%$ for the $\mathrm{R}^{2}$ value and a significant gender effect, therefore resulting in two different indexes for females and males, as follows:

$$
\begin{aligned}
\text { Female BeW }= & -48.8+0.087 \times \mathrm{AC}(\mathrm{cm})+1.147 \\
& \times \mathrm{HC}(\mathrm{cm})-0.003 \times \mathrm{HC}(\mathrm{cm})^{2}
\end{aligned}
$$

$$
\begin{aligned}
\text { Male BeW }= & -48.8+0.087 \times \mathrm{AC}(\mathrm{cm})+1.147 \\
& \times \mathrm{HC}(\mathrm{cm})-0.003 \times \mathrm{HC}(\mathrm{cm})^{2}-7.195
\end{aligned}
$$

New anthropometric index validation and performance The new equations of the BeW index were tested for the MVD and showed a good correlation, accuracy, and $\mathrm{CCC}(r=0.74 ; \mathrm{Cb}=0.94$; and $\mathrm{CCC}=0.70$, respectively) with BF\% estimated by ADP (Fig. 2). Although in a less extend, BF\% estimated by ADP also showed a good correlation, accuracy, and CCC with BAI $(r=0.67$, $\mathrm{Cb}=0.82$; and $\mathrm{CCC}=0.55$, Fig. 3 ); however, the $\mathrm{BeW}$ index provided lower limits (6.8 to $7.9 \%$, Fig. 2) of agreement with BF\% estimated by ADP than those obtained from the BAI ( -7.5 to $14.8 \%$, Fig. 3 ). Therefore, the $\mathrm{BF} \%$ values estimated by the $\mathrm{BAI}$ are, on average, $3.7 \%$ higher than those estimated by ADP, compared to $0.4 \%$ for the new index.

\section{Discussion}

Excessive BF is associated with the occurrence of clinical complications that compromise the quality of life and survival of individuals, such as diabetes, hypertension, cardiovascular disease, musculoskeletal disorders, and cancer [17]. Clinical assessments of BF\% in severely obese patients are challenged by the high cost of available methods and the lack of accuracy that some of these methods provide under the elevated fat, total and extracellular water, and change in electrolyte concentration exhibited by severely obese patients [3]. Aiming to solve this issue, we proposed a new equation involving simple anthropometric data to estimate BF\% specifically in severely obese patients.
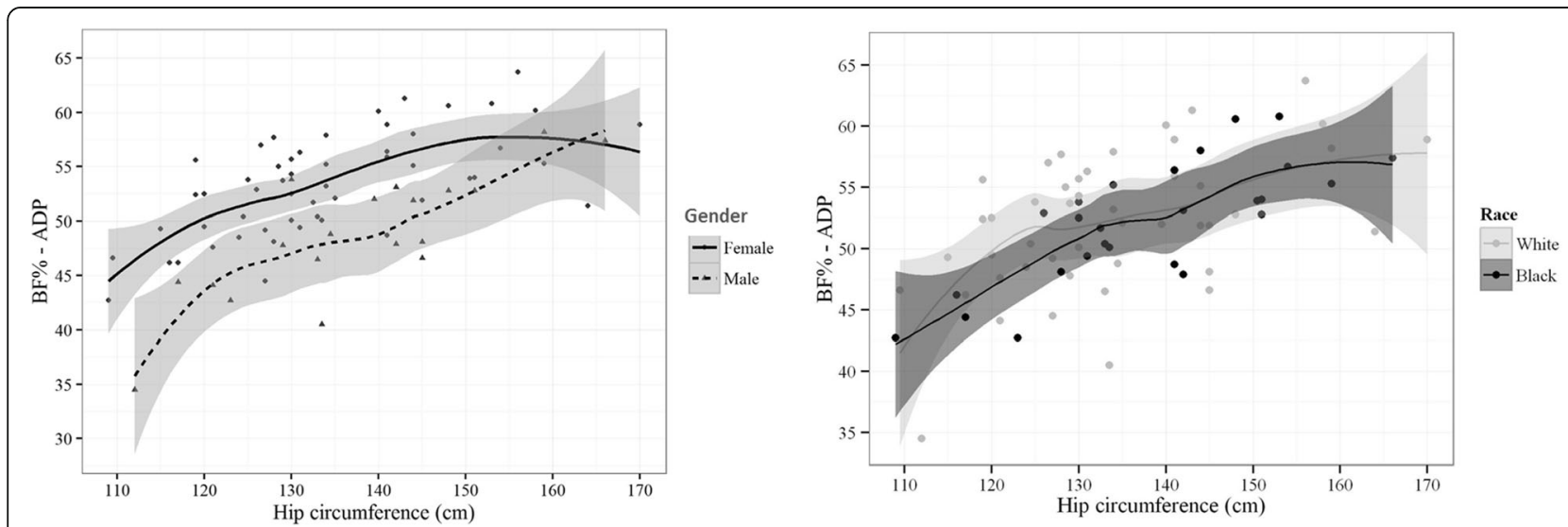

Fig. 1 Dispersion graphs of the body fat values (\%) estimated by air displacement plethysmography with hip circumference, gender, and race in the model building database. Data were obtained from 72 severely obese patients. The estimated curves were generated by the local polynomial regression method to best describe the data behavior. Note that for gender, the ratio of values of body fat (\%) estimated by air displacement plethysmography is not linear, and a curve trend of second order (quadratic) seems to be a good fit to the data. However, for race, there was no effect 
Table 3 Coefficients estimated for the initial prediction model for values of body fat (\%) estimated by air displacement plethysmography in the model building database

\begin{tabular}{|c|c|c|c|c|}
\hline Coefficient & Estimate & $\begin{array}{l}\text { Standard } \\
\text { Error }\end{array}$ & $\begin{array}{l}\mathrm{t} \\
\text { Value }\end{array}$ & $\begin{array}{l}p \\
\text { Value }\end{array}$ \\
\hline Intercept & -73.52 & 47.35 & -1.55 & 0.126 \\
\hline$A C(\mathrm{~cm})$ & 0.07 & 0.07 & 1.07 & 0.288 \\
\hline Body weight (kg) & 0.01 & 0.07 & 0.20 & 0.845 \\
\hline $\mathrm{HC}(\mathrm{cm})$ & 1.55 & 0.69 & 2.23 & 0.030 \\
\hline$(\mathrm{HC}(\mathrm{cm}))^{2}$ & -0.01 & 0.00 & -2.00 & 0.051 \\
\hline Sex - Male & 41.44 & 88.00 & 0.47 & 0.640 \\
\hline Race - brown/black & -2.44 & 78.92 & -0.03 & 0.976 \\
\hline AC (cm): male & 0.13 & 0.14 & 0.91 & 0.367 \\
\hline Body weight (kg): male & -0.14 & 0.12 & -1.13 & 0.262 \\
\hline $\mathrm{HC}(\mathrm{cm}):$ sex - male & -0.93 & 1.30 & -0.72 & 0.477 \\
\hline$(\mathrm{HC}(\mathrm{cm}))^{2}:$ sex - male & 0.00 & 0.00 & 0.92 & 0.362 \\
\hline AC (cm): race - brown/black & -0.12 & 0.16 & -0.75 & 0.459 \\
\hline $\begin{array}{l}\text { Body weight }(\mathrm{kg}) \text { : race - } \\
\text { brown/black }\end{array}$ & 0.09 & 0.11 & 0.80 & 0.426 \\
\hline $\mathrm{HC}(\mathrm{cm})$ : race - brown/black & 0.14 & 1.18 & 0.12 & 0.904 \\
\hline$(\mathrm{HC}(\mathrm{cm}))^{2}$ : race - brown/black & 0.00 & 0.00 & -0.17 & 0.868 \\
\hline
\end{tabular}

$R^{2}=57.3 \%$

Data were obtained from 72 obese patients. $A C$ abdominal circumference, $H C$ hip circumference

Our study was inspired by the BAI developed by Bergman and colleagues [6]. This tool was designed for $\mathrm{BF} \%$ assessment, and its most relevant aspects are the simplicity with which it is clinically applied and its higher performance than the BMI to identify and classify obesity. However, this tool has shown a low accuracy at estimating $\mathrm{BF} \%$ in several populations of severely obese patients $[9,10,18-21]$. These observations highlight that the BAI may not exceed the BMI limitations

Table 4 Estimated coefficients of the final prediction model for values of body fat (\%) estimated by air displacement plethysmography in the model building database

\begin{tabular}{lllll}
\hline Coefficient & Estimate & $\begin{array}{l}\text { Standard } \\
\text { Error }\end{array}$ & $\begin{array}{l}\mathrm{t} \\
\text { Value }\end{array}$ & $\begin{array}{l}p \\
\text { Value }\end{array}$ \\
\hline Intercept & -48.805 & 33.124 & -1.473 & 0.145 \\
$\begin{array}{l}\text { Abdominal circumference } \\
\text { (cm) }\end{array}$ & 0.087 & 0.035 & 2.439 & 0.017 \\
Hip circumference $(\mathrm{cm})$ & 1.147 & 0.486 & 2.358 & 0.021 \\
$(\text { Hip circumference }(\mathrm{cm}))^{2}$ & -0.003 & 0.002 & -1.981 & 0.052 \\
Sex - Male & -7.195 & 1.123 & -6.405 & $<$ \\
& & & & 0.001 \\
$\mathrm{R}^{2}=59.4 \%$ & & & & \\
\hline
\end{tabular}

Data were obtained from 72 obese patients when applied to assess body composition in severely obese patients [22].

For instance, Geliebter and colleagues compared the $\mathrm{BAI}$ and $\mathrm{BMI}$ performances in estimating the $\mathrm{BF} \%$ of severely obese women, using ADP, DXA, and body impedance analysis (BIA) as reference methods [20]. They found that body adiposity estimated by the BMI has a higher correlation with that estimated by ADP, bioelectrical impedance analysis (BIA), or DXA than by BAI. The authors concluded that the BAI seems to be a reasonable method to evaluate $\mathrm{BF} \%$, but it should not be used for this purpose in severely obese patients.

The reasons that the BAI is a poor indicator of $\mathrm{BF} \%$ in severely obese patients may be associated with the use of AC without applying distinct cutoff points for men and women. Obesity is characterized by a distinct fat accumulation between genders, the so-called android and gynoid obesities [23]. Men have a greater fat accumulation in the abdominal area, while in women this occurs in the hip. This feature allows differentiating the body compositions of men and women and may be more pronounced in severely obese patients due the marked fat accumulation.

In fact, by not considering specific male and female cutoffs, the BAI may become a weak tool for $\mathrm{BF} \%$ evaluation by gender. In a study of the general Mexican-American population, Lichtash and colleagues found that the BAI was a better indicator to estimate body adiposity than the BMI, compared to the reference values of DXA [24]. However, when the authors stratified the population by gender, the BAI had a lower performance than BMI for the same purpose. Notably, when reviewing the limitations for the BAI in assessing the BF\% in severely obese patients, Bernhard and colleagues found that significant errors of this variable estimation by BAI were determined by specific factors that included waist-hip ratio $\geq 1.05-5 \%$, gender, and obesity grade [19].

In our study, a poor performance of the BAI in estimating the $\mathrm{BF} \%$ in severely obese patients was confirmed. For both the MBD and MVD, the BAI underestimated the BF\% compared to ADP. Furthermore, we observed that the $\mathrm{BF} \%$ and $\mathrm{HC}$ were not linear between genders. This finding supports a potential need for the design of specific indexes for men and women. In fact, when we designed the new index stratified by gender, we observed better limits of individual agreement of ADP with the BeW index than with the BAI.

The experimental protocol of this study has both strengths and weaknesses. Our sample enrolled mostly severely obese patients $(\mathrm{BMI}=47.11 \pm 6.48)$, and this feature was decisive when choosing the 


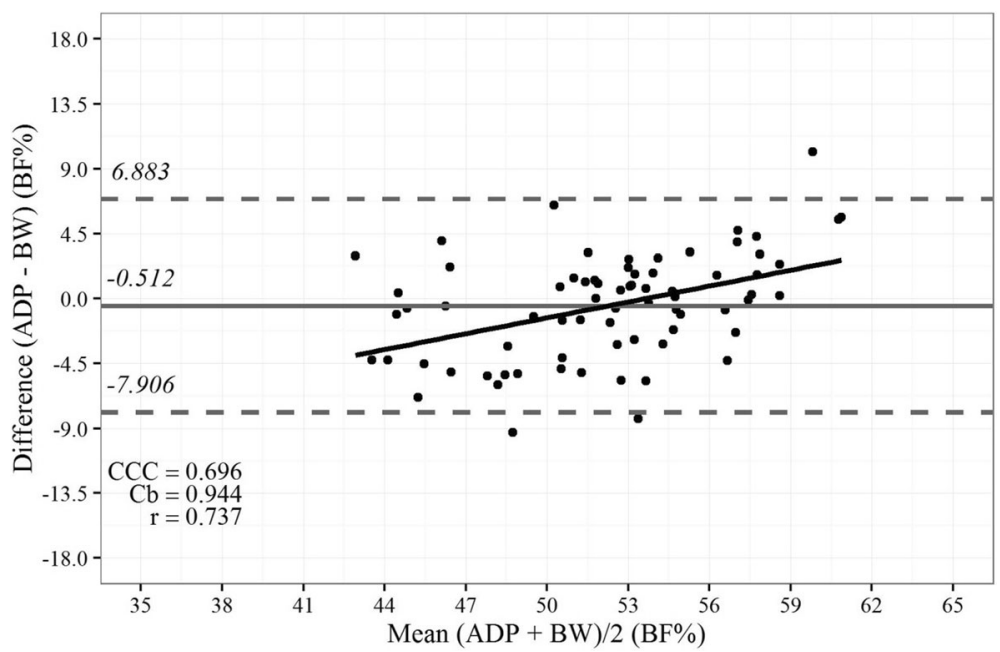

Fig. 2 Bland-Altman plot showing limits of agreement between the values of body fat (\%) estimated by air displacement plethysmography (ADP) vs. those estimated by the new Belarmino-Waitzberg (BeW) index in the validated model sample. Data were obtained from 72 severely obese patients. Bold continuous lines indicate the observed average agreement. Continuous lines indicate the line of perfect average agreement. Dashed lines indicate $95 \%$ limits of agreement. Lin's concordance correlation coefficient (CCC) is shown

reference method for $\mathrm{BF} \%$ assessment. $\mathrm{ADP}$ is a noninvasive method with a high accuracy for BF\% estimation from the body density, which has been validated in severely obese patients [2, 4, 25-30]. Several studies have used DXA as a reference method for body composition [6, 9, 20, 24, 31]. However, DXA devices have limited support for weight and width, which can prevent the proper function of the whole-body scanner for severely obese patients [3]. By using ADP as the reference method, we were able to assess the performance of the new index with reliable parameters. On the other hand, our sample was relatively small compared to most available related studies. Nevertheless, it had an effect size of at least 0.15 , considering an alpha value of $5 \%$ and a power of $95 \%$.

\section{Conclusion}

In summary, our study supports that the BAI may not be reliable for $\mathrm{BF} \%$ estimation in severely obese patients.

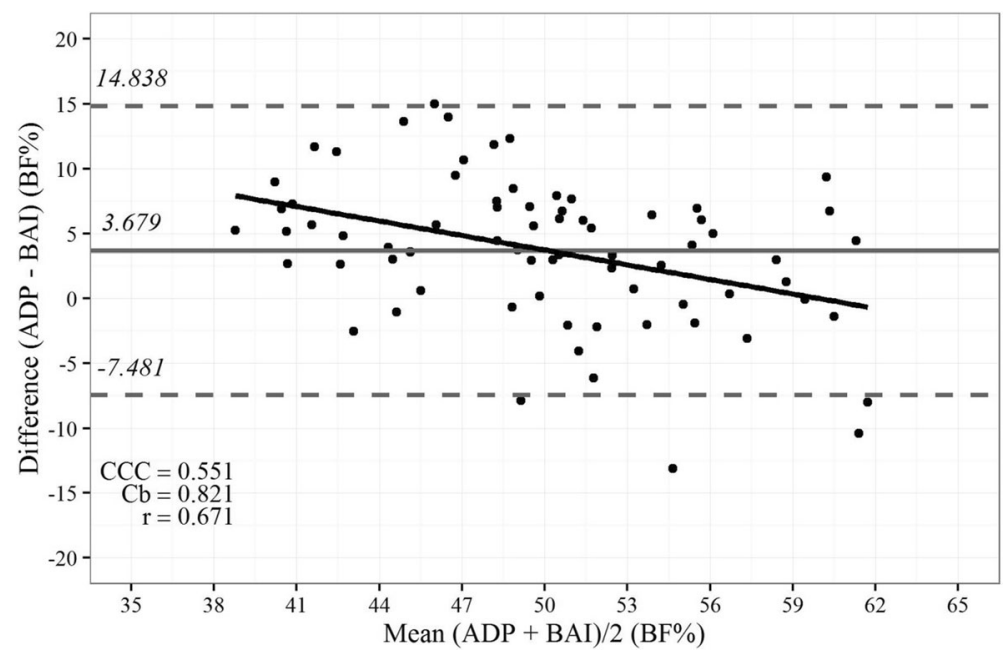

Fig. 3 Bland-Altman plot showing limits of agreement between the values of body fat (\%) estimated by air displacement plethysmography (ADP) vs. those estimated by the body adiposity index (BAl) in the validated model sample. Data were obtained from 72 severely obese patients. Bold continuous lines indicate the observed average agreement. Continuous lines indicate the line of perfect average agreement. Dashed lines indicate $95 \%$ limits of agreement. Lin's concordance correlation coefficient (CCC) is shown 
In the present study, the new BeW index developed to assess BF\% in severely obese patients showed a better performance than the BAI and followed a design that ensures its easy application. Therefore, replacement of the BAI with the new BeW index should be considered when assessing the adiposity level in patients with severe obesity.

\section{Abbreviations}

AC: Abdominal circumference; ADP: Air displacement plethysmography; BAl: Body adiposity index; BeW: Belarmino-Waitzberg; BF: Body fat; BMD: Building model database; BMl: Body mass index; Cb: Accuracy; CCC: Lin's concordance correlation; DXA: Dual-energy X-ray absorptiometry; HC: Hip circumference; r: Pearson correlation; VMD: validation model database

\section{Acknowledgements}

The authors thank the patients and nurses who participated in the study and Fundação de Amparo à Pesquisa do Estado de São Paulo (FAPESP).

\section{Funding}

This work was supported by Fundação de Amparo a Pesquisa do Estado de São Paulo (FAPESP), project no. 2011/09612-3 and 2011/13243-3, DD 2012/ 15677-3.

\section{Availability of data and materials}

The datasets used and/or analysed during the current study are available from the corresponding author on reasonable request.

\section{Authors' contributions}

GB and RST contributed to the conception and design of the study. GB, RST, PS, LMH, LD, NCL, SBH, DLW were responsible for the acquisition, analysis, and/or interpretation and discussion of data. GB, RST, NCL, SBH and DLW drafted the manuscript. GB and RST participated in study design and coordination and helped to draft the manuscript. GB, RST and LD participated in the design of the study and performed the statistical analysis. LD performed statistical analyses. All authors read and approved the final manuscript.

\section{Ethics approval and consent to participate}

All study procedures were performed according to the ethical standards of the World Medical Association's Declaration of Helsinki. These and both datasets (building and validation) were approved by the institutional ethics review board - CAPPesq (1069/05 and 1011/09). Written informed consent was obtained from each patient prior to trial participation.

\section{Consent for publication}

Not applicable.

\section{Competing interests}

The authors declare that they have no competing interests.

\section{Publisher's Note}

Springer Nature remains neutral with regard to jurisdictional claims in published maps and institutional affiliations.

\footnotetext{
Author details

${ }^{1}$ Department of Gastroenterology, Surgical Division, LIM 35, Faculdade de Medicina da Universidade de São Paulo, Av. Dr. Arnaldo, 455, $2^{\circ}$ andar, sala 2208, São Paulo, Cerqueira César CEP: 01246-903, Brazil. ${ }^{2}$ Research Institute Hospital do Coração de São Paulo, São Paulo, Brazil. ${ }^{3}$ Pennington Biomedical Research Center, Baton Rouge, LA, USA.
}

Received: 14 May 2017 Accepted: 7 June 2018

Published online: 01 October 2018

\section{References}

1. Patel D. Pharmacotherapy for the management of obesity. Metab Clin Exp. 2015;64:1376-85.
2. Das SK. Body composition measurement in severe obesity. Curr Opin Clin Nutr Metab Care. 2005:8:602-6.

3. Beechy L, Galpern J, Petrone A, Das SK. Assessment tools in obesity psychological measures, diet, activity, and body composition. Physiol Behav. 2012;107:154-71.

4. Ginde SR, Geliebter A, Rubiano F, Silva AM, Wang J, Heshka S, Heymsfield SB. Air displacement plethysmography: validation in overweight and obese subjects. Obes Res. 2005 Jul;13(7):1232-7.

5. Fields DA, Goran MI, McCrory MA. Body-composition assessment via airdisplacement plethysmography in adults and children: a review. Am J Clin Nutr. 2002 Mar;75(3):453-67.

6. Bergman RN, Stefanovski D, Buchanan TA, Sumner AE, Reynolds JC, Sebring NG, et al. A better index of body adiposity. Obesity (Silver Spring). 2011;19:1083-9.

7. Esco MR. The accuracy of the body adiposity index for predicting body fat percentage in collegiate female athletes. J Strength Cond Res. 2013: 27:1679-83

8. Lemacks JL, Liu PY, Shin H, Ralston PA, Ilich JZ. Validation of body adiposity index as a measure of obesity in overweight and obese postmenopausal white women and its comparison with body mass index. Menopause. 2012;19:1277-9.

9. Segheto W, Coelho FA, Silva DCG, Hallal PC, Marins JCB, Ribeiro AQ, et al. Validity of body adiposity index in predicting body fat in Brazilian adults. Am J Hum Biol. 2017;29(1).

10. Belarmino G, Horie LM, Sala PC, Torrinhas RS, Heymsfield SB, Waitzberg DL. Body adiposity index performance in estimating body in fat in a sample of severely obese Brazilian patients. Nutr J. 2015;14:130-6.

11. Cohen J. Statistical power analysis for the behavioral sciences. 2nd ed. Hillsdale: Lawrence Erlbaum Associates; 1988.

12. Heyward VH, Wagner DR. Applied body composition assessment, 2nd ed. Champaign: Human Kinetics; 2004.

13. Histórico da investigação sobre cor ou raça nas pesquisas domiciliares do IBGE. Notas técnicas do IBGE 2008. Available at http://www.ibge.gov.br/. Accessed 3 Oct 2016.

14. Sartorio A, Conte G, Morini P, Battistini N, Faglia G, Bedogni G. Changes of bioelectrical impedance after a body weight reduction program in highly obese subjects. Diabetes Nutr Metab. 2000;13:186-91.

15. Keys A, Fidanza F, Karvonen MJ, Kimura N, Taylor HL. Indices of relative weight and obesity. J Chronic Dis. 1972;25:329-43.

16. Haskell WL, Lee IM, Pate RR, Powell KE, Blair SN, Franklin BA, et al. Physical activity and public health: updated recommendation for adults from the American College of Sports Medicine and the American Heart Association. Med Sci Sports Exerc. 2007;39:1423-34.

17. Swinburn BA, Caterson I, Seidell JC, James WP. Diet, nutrition and the prevention of excess weight gain and obesity. Public Health Nutr. 2004 7:123-46

18. Cerqueira M, Amorim P, Magalhães F, Castro E, Franco F, et al. Validity of body adiposity index in predicting body fat in a sample of Brazilian women. Obesity (Silver Spring). 2013;21:E696-9.

19. Bernhard AB, Scabim VM, Serafim MP, Gadducci AV, Santo MA, de Cleva R. Modified body adiposity index for body fat estimation in severe obesity. J Hum Nutr Diet. 2017;30:177-84.

20. Geliebter A, Atalayer D, Flancbaum L, Gibson CD. Comparison of body adiposity index (BAl) and body mass index (BMI) with estimations of \% body fat in clinically severe obese women. Obesity (Silver Spring). 2013; 21:493-8

21. Gibson CD, Atalayer D, Flancbaum L, Geliebter A. Body adiposity index (BAI) correlates with BMI and body fat pre- and post-bariatric surgery but is not an adequate substitute for BMl in severe obese women. Int J Body Compos Res. 2012:10:9-14.

22. Bennasar-Veny M, Lopez-Gonzalez AA, Tauler P, Cespedes ML, VicenteHerrero $T$, et al. Body adiposity index and cardiovascular health risk factors in Caucasians: a comparison with the body mass index and others. PLoS One. 2013;8:e63999.

23. Molarius A, Seidell JC. Selection of anthropometric indicators for classification of abdominal fatness - a critical review. Int J Obes. 1998;12:719-27.

24. Lichtash CT, Cui J, Guo X, Chen YDI, Hsueh WA, et al. Body adiposity index versus body mass index and other anthropometric traits as correlates of Cardiometabolic risk factors. PLoS One. 2013;8:e65954.

25. Le Carvennec M, Fagour C, Adenis-Lamarre E, Perlemoine C, Gin H, Rigalleau V. Body composition of obese subjects by air displacement 
plethysmography: the influence of hydration. Obesity (Silver Spring). 2007;15:78-84.

26. Hames KC, Anthony SJ, Thornton JC, Gallagher D, Goodpaster BH. Body composition analysis by air displacement plethysmography in normal weight to extremely obese adults. Obesity (Silver Spring). 2014;22:1078-84.

27. Bedogni G, Agosti F, De Col A, Marazzi N, Tagliaferri A, et al. Comparison of dual-energy $\mathrm{X}$-ray absorptiometry, air displacement plethysmography and bioelectrical impedance analysis for the assessment of body composition in morbidly obese women. Eur J Clin Nutr. 2013;67:1129-32.

28. Petroni ML, Bertoli S, Maggioni M, Morini P, Battezzati A, et al. Feasibility of air plethysmography (BOD POD) in morbid obesity: a pilot study. Acta Diabetol. 2003;40(Suppl 1):S59-62

29. Plasqui G, Soenen S, Westerterp-Plantenga MS, Westerterp KR. Measurement of longitudinal changes in body composition during weight loss and maintenance in overweight and obese subjects using air-displacement plethysmography in comparison with the deuterium dilution technique. Int J Obes. 2011:35:1124-30

30. Wingfield HL, Smith-Ryan AE, Woessner MN, Melvin MN, Fultz SN, Graff RM. Body composition assessment in overweight women: validation of air displacement plethysmography. Clin Physiol Funct Imaging. 2014;34:72-6.

31. Zhang ZQ, Liu YH, Xu Y, Dai XW, Ling WH, et al. The validity of the body adiposity index in predicting percentage body fat and cardiovascular risk factors among Chinese. Clin Endocrinol. 2014;81:356-62.

Ready to submit your research? Choose BMC and benefit from:

- fast, convenient online submission

- thorough peer review by experienced researchers in your field

- rapid publication on acceptance

- support for research data, including large and complex data types

- gold Open Access which fosters wider collaboration and increased citations

- maximum visibility for your research: over $100 \mathrm{M}$ website views per year

At BMC, research is always in progress.

Learn more biomedcentral.com/submissions 